\title{
PLANEJAMENTO ESTRATÉGICO: OPERAÇÃO E RESULTADOS
}

\author{
OSS SANTA MARCELINA ITAQUAQUECETUBA
}

\section{Autores: Alexander de Sá Rolim, Elaine Reis Caraça, Felipe Moulin, Ferdinando Borrelli, Ir. Tereza} Aparecida Teixeira e Marcos Eduardo Moreto.

\section{INTRODUÇÃO}

O Hospital de Itaquaquecetuba é uma Organização Social de Saúde (O.S.S.) localizada no Alto Tietê que oferece atendimento de Pronto Socorro com média/mês de 4990 e Ambulatório com média/mês 2679 (2017). Devido ao mercado político atual e período financeiro volátil foi readequado o planejamento estratégico seguindo o conceito do BSC para a atualização.

\section{DESENVOLVIMENTO}

Plano de ação: Conforme a lei 8080/90 que rege as Organizações Sociais de Saúde (sem fins lucrativos) foi necessário ajuste da perspectiva financeira para sustentabilidade visando a manutenção do repasse e otimização dos investimentos sem alterar as demais perspectivas. A última atualização ocorrida em 2017 teve o objetivo de executar ações para redução da média de permanência e da densidade de infecção. Na atualização de 2018 a visão não foi alterada: "Ser instituição com Gestão Integrada até 2020". Houve ainda ações para reestruturação dos indicadores, divulgação das iniciativas estratégicas, revisão do mapa estratégico junto aos objetivos, alterações no acompanhamento dos resultados, porém mantido o objetivo central com modificações na operação tática.

Execução: Em 2017 e 2018 foram realizadas reuniões mensais divididas em áreas assistenciais e apoio com correlação dos indicadores, sendo estes analisados quanto à média de permanência e densidade de infecção, com foco na avaliação da operação das ações por meio da aplicação do PDSA. Como conceito para divulgação dos resultados foi inserido os painéis "Gestão à Vista" com a exposição dos indicadores e apresentação. Frente aos resultados alcançados em 2017 e 2018 a atualização foi realizada com o intuito de estabelecer as interações entre as áreas, indicadores atrelados ao planejamento estratégico e mudança nas reuniões. Em 2019 será atribuída nova metodologia para as reuniões que serão divididas em: Reunião de Análise Tática e Reunião de Análise Estratégica.

\section{CONCLUSÃO}

\section{Resultados:}

$\checkmark$ Redução da média de permanência em 15\% (média de 2017: 8,07 para 2018: 7,02)*;

$\checkmark$ Redução da densidade global de infecção em 18\% (média de 2017: $3,75$ para $2018: 3,18)^{*}$

$\checkmark$ Redução da taxa de mortalidade em 12\% (média de 2017: 6,21\% para 2018: 5,55\%)*.

*Dados em relação ao mesmo período janeiro/2017 a dezembro/2018

\section{LIÇÕES APRENDIDAS}

$\checkmark$ Acompanhamento periódico dos resultados;

$\checkmark$ Desdobramento das iniciativas estratégicas para a operação;

$\checkmark$ Foco no resultado planejado;

$\checkmark$ Avaliação do mercado externo;

$\checkmark$ Divulgação dos resultados para todos os colaboradores.

\section{REFERÊNCIAS}

Kaplan R, S. A Execução Premium. Ed. Campus. Rio de Janeiro. 2009. Costa E, A. Gestão Estratégica. Ed. Saraiva. São Paulo. 2013.
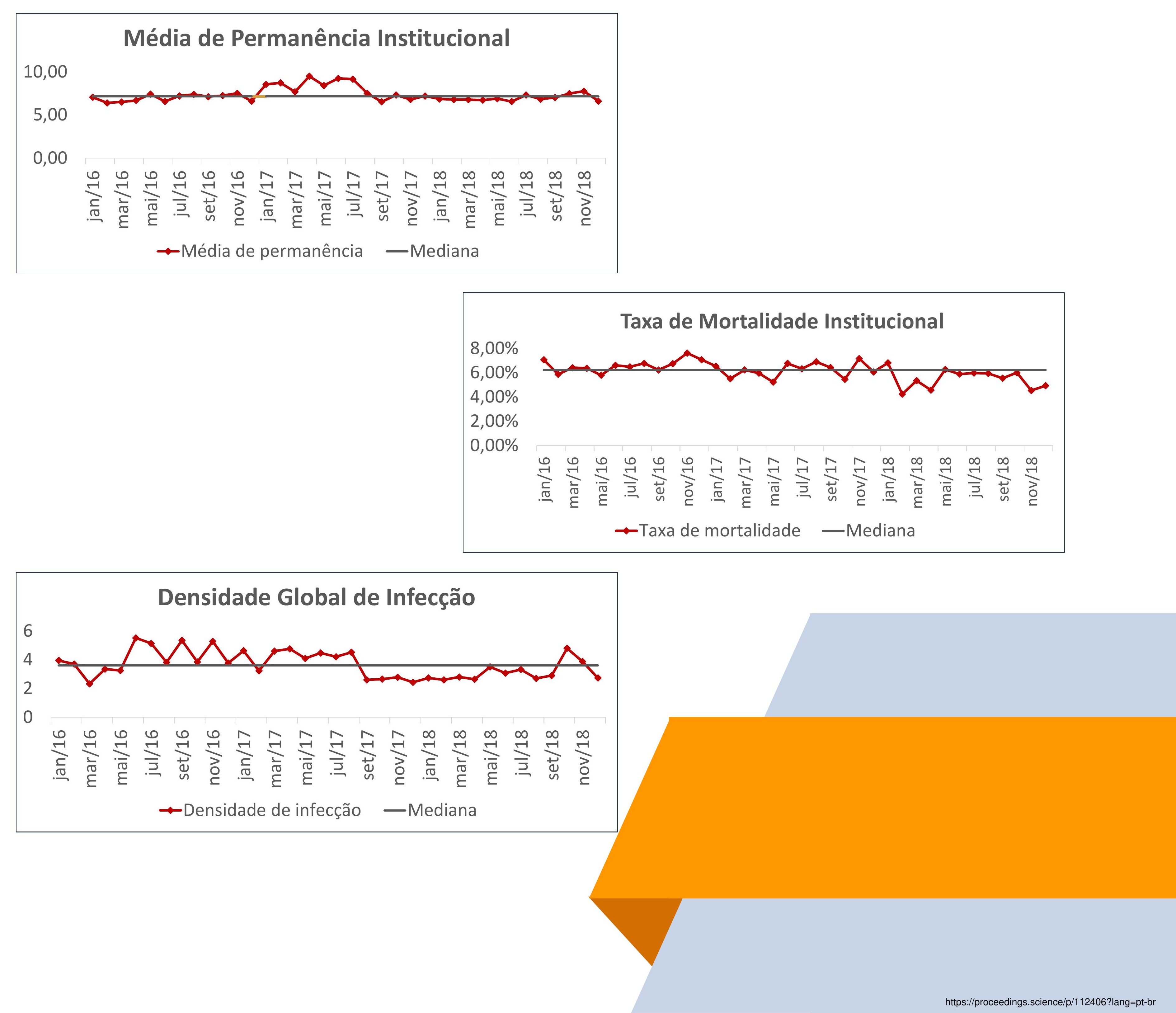